\title{
Evaluation of Topical Mitomycin-C Eye Drops After Reconstructive Surgery for Anophthalmic Contracted Socket
}

\author{
Hala K Mattout (D) \\ Sameh M Fouda \\ Haitham Y Al-Nashar \\ Ophthalmology Department, Faculty of \\ Medicine, Zagazig University, Zagazig, \\ Egypt
}

Purpose: To report the outcomes of using topical mitomycin-C (MMC) after reconstructive surgery for contracted socket and to compare the results with those of the conventional postoperative treatment.

Patients and Methods: The medical records of patients who underwent reconstructive surgery for contracted anophthalmic socket were retrospectively reviewed. Based on the postoperative treatment protocol, two groups of patients were identified; group I (15 patients) who received topical MMC drops (0.02\%) 4 times daily for 6 weeks and group II (15 patients) who received the conventional treatment (topical antibiotic-steroid combination). Preoperative data were extracted for age, gender, cause and timing of anophthalmia, history of previous surgeries, preoperative forniceal depth and socket volume (SV). The main postoperative outcome measures were superior fornix depth (SFD), inferior fornix depth (IFD) and SV at the end of 6th postoperative month. Prosthesis fitting and complications were also considered for analysis.

Results: The mean preoperative IFD was $1.67 \pm 0.04 \mathrm{~mm}$ in group I and $1.58 \pm 0.37 \mathrm{~mm}$ in group II, by the end of the 6th postoperative month it increased to $6.1 \pm 0.27 \mathrm{~mm}$ and 5.12 $\pm 0.25 \mathrm{~mm}$, respectively. The mean preoperative SFD in group I was $8.3 \pm 0.9 \mathrm{~mm}$ and 8.9 $\pm 1.1 \mathrm{~mm}$ in group II, by the end of the 6th postoperative month SFD became $13.4 \pm 1.2 \mathrm{~mm}$ and $10.2 \pm 1.4 \mathrm{~mm}$ in groups I and II, respectively. The mean SV measured six months postoperatively was $1.9 \pm 0.2 \mathrm{~mL}$ and $1.3 \pm 0.09 \mathrm{~mL}$ in groups I and II, respectively. These differences in the postoperative SFD, IFD and SV between both groups were statistically significant. More cases reported successful fitting in group I than in group II but this difference was not statistically significant.

Conclusion: Postoperative use of topical MMC is associated with higher forniceal depth and greater SV when compared to the conventional treatment in socket reconstructive surgeries with amniotic membrane graft (AMG).

Keywords: contracted socket, mitomycin-C, amniotic membrane graft, anophthalmic socket, MMC, AMG

\section{Introduction}

Contracted socket is considered a common complication in anophthalmic patients with a resulting poor fitting of ocular prosthesis. ${ }^{1}$ It is characterized by fibrosis and reduction in conjunctival surface area along with reduction of the forniceal depth. This incriminated fibrosis is usually caused by severe initial or subsequent infection or by extensive surgical dissection of orbital tissue with excessive destruction of conjunctiva and Tenon's capsule., $^{2,3}$
Correspondence: Hala K Mattout Ophthalmology Department, Faculty of Medicine, Zagazig University, Zagazig, Egypt

Email halamattout@gmail.com; HKMtoot@medicine.zu.edu.eg 
Management of acquired anophthalmic socket contracture mainly involves replacement of the cicatricial conjunctival tissue with a healthy graft to re-establish a deep fornix that allows a proper subsequent fitting of an ocular prosthesis. ${ }^{4}$ Many surgical techniques are available to reconstruct the contracted socket including; mucous membrane graft from buccal or nasal mucosa, nasal septum, or soft palate, split thickness skin graft and amniotic membrane graft (AMG). All of them are good choices to reconstruct the fornices according to the surgeon's and patient's preferences and according to the severity and cause of socket contraction as amniotic membrane for instance is usually more used in mild to moderate cases of contracted socket with no history of radiotherapy. ${ }^{5,6}$

The main goal of anophthalmic orbital reconstructive surgery is to allow the patient to use a suitable and wellfitted ocular prosthesis that simulates - as much as possible - the normal fellow eye. ${ }^{7}$

Prevention of postoperative conjunctival fibrosis is the main key for successful socket reconstructive surgery. However, even after careful and meticulous surgical manipulations, repeated socket contraction can occur. ${ }^{8}$

Mitomycin-C (MMC) is an alkylating antimetabolite agent which acts by inhibiting DNA synthesis with significant ability to suppress fibroblasts proliferation and activity, thus causing a significant reduction of scarring in vitro and in vivo. MMC has been used successfully in glaucoma surgery to prevent recurrence by inhibiting subconjunctival fibrosis. In addition, it is a relatively safe and effective line of treatment in surgeries for pterygium, ocular surface neoplasia and nasolacrimal duct obstruction. ${ }^{9-12}$

Previous studies found that the intraoperative and postoperative injection of antimetabolites (MMC and 5Fluorouracil $[5 \mathrm{FU}])$ is effective for the treatment of contracted socket. ${ }^{9,10}$

The aim of this retrospective study is to report the outcomes of using topical MMC eye drops after reconstructive surgery for contracted socket, and to compare the results with those of the conventional postoperative topical treatment.

\section{Patients and Methods}

The medical records of patients who underwent reconstructive surgery for contracted anophthalmic socket were retrospectively reviewed. Patients included in this analysis were those who had contracted anophthalmic socket either primary or recurrent with no signs of infection, no history of irradiation, age above 25 , no implant migration and those who attended their follow up visits. All patients were operated at the ophthalmology department of Zagazig University Hospital during the period between January 2018 and January 2020. This study was approved by the institutional review board of the Faculty of Medicine, Zagazig University and was carried out in accordance with the tenets of the Declaration of Helsinki of 1964, as revised in 2013. A written informed consent was provided by all patients.

Based on the postoperative treatment protocol; two groups of patients were identified; Group I who received topical MMC eye drops (0.02\%) 4 times daily for 6 weeks and group II who received the conventional medical treatment.

Preoperative data were extracted for age, gender, cause and timing of evisceration or enucleation, history of previous surgeries for contracted socket, degree of socket contracture, preoperative forniceal depth and volume of the socket. The follow up data were collected after 2 weeks, one month, three months and 6 months following the procedure.

The socket contracture severity was classified according to Tawfik et $\mathrm{al}^{13}$ into 5 grades. Grade 1: minimal contraction with shallow or shelved lower fornix, grade 2: mild contracture with loss of the inferior and/or the superior fornix, grade 3: more advanced cicatrization involving the entire fornices, grade 4: severe phimosis of the palpebral fissure both vertically and horizontally, grade 5: recurrent contracted socket. All patients had received topical antibiotic eye drops as a routine prior to surgery.

All patients received an AMG for socket reconstruction. Incision was made in the area of maximum contraction whether at the inferior fornix alone or in both fornices according to the severity of socket contraction, lateral canthotomy with inferior cantholysis were performed only with narrow palpebral fissure. Meticulous dissection to excise all fibrous tissue was done with extra-care applied when dealing with the superior fornix to avoid injury of the levator muscle, the resulting defect was measured in both horizontal and vertical dimensions and an $\mathrm{AMG}$ of a size $50 \%$ more than the resulting defect is secured to the surrounding conjunctiva with interrupted 6/ 0 polyglactin sutures and to the underlying bed with quilt sutures technique. Three lower fornix deepening sutures were applied using 4-0 double armed prolene suture passing through a silicone retinal band then through orbital periosteum before exiting from the skin side followed by 
application of a well fitted conformer before tying the fornix sutures over cotton bolsters to ensure adequate fornix deepening effect. In cases where upper fornix deepening sutures were indicated, two sutures on both sides of the levator complex were applied using the same technique and passing through the periosteum of the superior orbital rim. A central temporary tarsorrhaphy suture was taken to retain the conformer in place. Fornix deepening sutures were left for 3 weeks and tarsorrhaphy suture was cut after 2 weeks.

All patients had received postoperative treatment in the form of broad spectrum oral antibiotic and oral analgesics for one week, topical combined antibiotic/steroid eye drops and ointment for 6 weeks. MMC eye drops were used in group I (15 eyes). MMC eye drops were prepared with a concentration of $0.02 \%(0.2 \mathrm{mg} / \mathrm{mL})$ and instilled 4 times/ day for 6 weeks. Patients in group II (15 eyes) received only the previously mentioned routine postoperative treatment. After 8 weeks, all patients were referred to the ocularist for adequate customized prosthesis fitting.

The main evaluated postoperative outcome measures taken at each follow up visit were:

1) The superior fornix depth (SFD) and inferior fornix depth (IFD): They were measured using a transparent sterile ruler placed vertically in the center of superior and inferior fornices as shown in Figure 1.

2) Socket volume (SV): It was measured by putting drop-by-drop saline in socket from a syringe with the patient lying in a supine position and noting the reading when the first drop overflowed.

The ability to retain prosthesis, prosthesis mobility and postoperative complications were also considered. Fitting

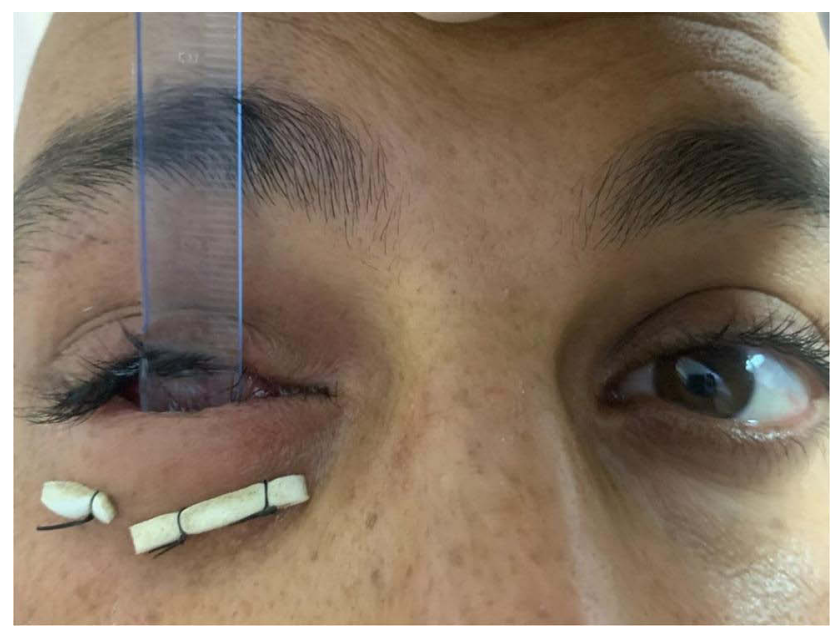

Figure I Measurement of IFD. of the prosthesis was taken as a secondary outcome measure and it was objectively graded as successful, acceptable and poor as follows:

1) Successful fitting was considered when the prosthesis fitted in both fornices without slippage nor tilt.

2) Acceptable fitting was considered when the prosthesis fitted in both fornices but showing tilt with eyelid movement (e.g., blinking).

3) Poor fitting was considered when the prosthesis could not be retained in place with spontaneous extrusion.

\section{Statistical Analysis}

The collected data were analysed using Statistical Package of Social Services, version 25 (SPSS) (IBM, 2017). Shapiro-Wilk test was used to determine the distribution characteristics of quantitative variables; normally distributed data were described using mean, standard deviation (SD) and analysed using independent samples $T$-test, while heterogeneous non-normally distributed data were described using median, interquartile range (IQR) and analysed using Mann-Whitney test.

Qualitative data were expressed as percentages, Fisher exact test and Pearson's chi-squared test were used to analyse them. In all the tests, the $\mathrm{P}$ value of $<0.05$ was taken as significant.

\section{Results}

Record review identified 30 patients meeting the inclusion criteria. Based on the administered postoperative treatment, two groups were identified; Group I (15 patients) who received topical MMC eye drops (0.02\%) 4 times daily for 6 weeks and group II (15 patients) who received the conventional medical treatment. The mean follow up period for all patients was $10 \pm 3.8$ months.

Table 1 shows the demographic data and preoperative characteristics of both groups with no detectable statistically significant difference between groups. The main causes of eye loss in both groups were blind painful eye secondary to absolute glaucoma or endophthalmitis in 13 patients $(43 \%)$, ocular malignancy in 10 patients $(33 \%)$ and severe ocular trauma in 7 patients (24\%). The mean numbers of previous surgeries for socket reconstruction in group I was $2.1 \pm 0.1$ surgeries in group I and $1.89 \pm 0.08$ surgeries in group II. All patients had previous orbital implant that was primary in 18 patients $(60 \%)$ and secondary in 12 patients $(40 \%)$. Grade of contracture ranged from 2 to 5 in both groups. Causes of contracted socket in both groups were also enlisted in Table 1 with no significant difference detected between them. 
Table I Preoperative Data of Patients Included in the Study

\begin{tabular}{|c|c|c|c|}
\hline & Group I & Group II & $P$ value \\
\hline Age (years) & $49.25 \pm 1.3$ (range: $34-57)$ & $50.1 \pm 1.4$ (range: $35-59)$ & 0.42 \\
\hline Sex & & & 0.1 \\
\hline Males & $8(53.3 \%)$ & $9(60 \%)$ & \\
\hline Females & $7(46.7 \%)$ & $6(40 \%)$ & \\
\hline Causes of anophthalmia & & & 0.8 \\
\hline Ocular malignancy & $5(33.3 \%)$ & $5(33.3 \%)$ & \\
\hline Ocular trauma & $4(26.7 \%)$ & $3(20 \%)$ & \\
\hline Blind painful eye & $6(40 \%)$ & $7(46.7 \%)$ & \\
\hline Causes of socket contraction & & & 0.8 \\
\hline Infection & $4(26.7 \%)$ & $3(20 \%)$ & \\
\hline Inappropriate prosthesis wearing & $4(26.7 \%)$ & $5(33.3 \%)$ & \\
\hline Chemical injury & $2(13.3 \%)$ & I (6.7\%) & \\
\hline Inadequate implant size & $2(13.3 \%)$ & $4(26.7 \%)$ & \\
\hline Presumed poor surgical technique & $3(20 \%)$ & $2(13.3 \%)$ & \\
\hline Number of prior surgeries & $2.1 \pm 0.1$ (range: $0-4$ ) & $1.89 \pm 0.08$ (range: $0-3$ ) & 0.35 \\
\hline Time elapsed since anophthalmia(year) & $4.25 \pm 0.2$ (range: $I-6)$ & $3.79 \pm 0.14$ (range: $1-5$ ) & 0.42 \\
\hline Grade of contracted socket & & & 0.8 \\
\hline Median (IQR) & $3(2)$ & $3(2)$ & \\
\hline
\end{tabular}

Regarding the surgical procedure, all patients had inferior fornix reconstruction, 10 patients (33\%) had both superior and inferior fornices reconstructed ( 6 patients in group I and 4 in group II).

The mean preoperative IFD was $1.67 \pm 0.04 \mathrm{~mm}$ in group I and $1.58 \pm 0.37 \mathrm{~mm}$ in group II with no significant difference between them. The postoperative mean IFD by the end of the sixth postoperative month was 6.1 $\pm 0.27 \mathrm{~mm}$ in group I and $5.12 \pm 0.25$ group II with statistically significant difference between them $(p=0.01)$. In group I, the mean preoperative SFD was $8.3 \pm 0.9 \mathrm{~mm}$ and in group II was $8.9 \pm 1.1 \mathrm{~mm}(\mathrm{p}=0.45)$. At 6 months postoperatively, the mean SFD was $13.4 \mathrm{~mm}$ and 10.2 in groups I and II respectively, this difference was statistically significant $(\mathrm{p}=0.01)$. These data along with those collected in the other follow up visits are represented in Table 2

In group I, the mean preoperative $\mathrm{SV}$ was $0.75 \pm 0.1 \mathrm{~mL}$ and in group II, it was $0.80 \pm 0.12 \mathrm{~mL}(\mathrm{p}=0.32)$. At final follow up, the mean $\mathrm{SV}$ was $1.9 \pm 0.2 \mathrm{~mL}$ and $1.3 \pm 0.09$ in groups I and II respectively with significant statistical difference $(\mathrm{p}=0.01)$. SV measurements in all follow up visits are shown in Table 3.

In both groups, highest measurements were seen in the second week following the procedure then gradual decrease in measurement values commenced 4 to 6 weeks after surgery and progressed thereafter. This progression was more evident in group II who did not receive topical MMC.

Table 2 Measurements of IFD, SFD at Various Follow-Up Visits for Both Groups

\begin{tabular}{|c|c|c|c|c|c|c|}
\hline \multirow[t]{2}{*}{ Time } & \multicolumn{3}{|c|}{ IFD (mm) (Mean \pm SD) } & \multicolumn{3}{|c|}{ SFD $(\mathrm{mm})($ Mean \pm SD) } \\
\hline & Group I & Group II & P value & Group I & Group II & $P$ value \\
\hline Pre- operative & $1.67 \pm 0.04(0-3.5)$ & $1.58 \pm 0.37(0-3)$ & 0.42 & $8.3 \pm 0.9(5-11)$ & $8.9 \pm 1.1(5.5-12)$ & 0.45 \\
\hline $2^{\text {nd }}$ week & $7.4 \pm 0.11(4-8.5)$ & $7.3 \pm 0.14(4-8)$ & 0.53 & $14.9 \pm 1.2(12-19)$ & $14.3 \pm 1.3(12-19.5)$ & 0.3 \\
\hline$I^{\text {st }}$ month & $7.3 \pm 0.18$ (4-9) & $7.1 \pm 0.21(4.5-8.5)$ & 0.35 & $14.5 \pm 0.7(12-18 / 5)$ & $|3.8 \pm 1|.(9-\mid 4)$ & 0.1 \\
\hline $3^{\text {rd }}$ month & $6.8 \pm 0.19(4-8.5)$ & $5.76 \pm 0.14(3.5-7)$ & $0.03 *$ & $14.1 \pm 0.9(11-18)$ & $10.9 \pm 1.1(8.5-13)$ & $0.02 *$ \\
\hline $6^{\text {th }}$ month & $6.1 \pm 0.27(3.5-8)$ & $5.12 \pm 0.25(3-6.5)$ & $0.01 *$ & $13.4 \pm 1.2(11-17)$ & $10.2 \pm 1.4(8-12)$ & $0.01 *$ \\
\hline
\end{tabular}

Note: *Statistically significant.

Abbreviations: IFD, inferior fornix distance measured in mm; SFD, superior fornix distance measured in $\mathrm{mm}$. 
Table 3 Measurements of SV at Various Follow-Up Visits for Both Groups

\begin{tabular}{|c|c|c|c|}
\hline \multirow[t]{2}{*}{ Time } & \multicolumn{3}{|c|}{ SV $(m L)($ Mean $\pm S D)$} \\
\hline & Group I & Group II & $P$ value \\
\hline Pre-operative & $0.75 \pm 0.1(0.45-I . I)$ & $0.80 \pm 0.12(0.5-1.2)$ & 0.32 \\
\hline $2^{\text {nd }}$ week & $2.6 \pm 0.3(1.9-3.2)$ & $2.5 \pm 0.1(1.8-3.2)$ & 0.45 \\
\hline$I^{\text {st }}$ month & $2.5 \pm 0.2(1.9-3.1)$ & $2.3 \pm 0.4(1.8-2.9)$ & 0.1 \\
\hline $3^{\text {rd }}$ month & $2.1 \pm 0.1(1.4-2.8)$ & $1.3 \pm 0.2(0.8-1.7)$ & $0.01 *$ \\
\hline $6^{\text {th }}$ month & $1.9 \pm 0.2(1.1-2.4)$ & $1.3 \pm 0.09(0.8-1.6)$ & $0.01 *$ \\
\hline
\end{tabular}

Note: *Statistically significant.

Abbreviation: SV, socket volume measured in $\mathrm{mL}$.

At six months after the operation, in group I, the prosthetic fitting was successful in 13 patients $(87 \%)$, acceptable in one case $(6.5 \%)$ and poor in one case $(6.5 \%)$ due to an inadequate lateral lower fornix. While in group II, the prosthetic fitting was successful in 9 patients $(60 \%)$, acceptable in 2 patients $(13.5 \%)$ and poor in 4 patients $(26.5 \%)$ due to complete recurrence of fornix contracture. However, those differences were statistically insignificant $(\mathrm{p}=0.2)$. Figure 2 shows a graphic presentation of these results.

No complications were reported in group I patients while 2 patients of group II developed granuloma that required excision - in the third and fifth months respectively - to allow adequate prosthesis fitting.

We present the following two cases as examples:

Case 1:

It was for a 53 year old female patient, with history of evisceration due to endophthalmitis. She had received secondary ball implantation with adequate prosthesis fitting but she had recurrent attacks of infected socket with poor compliance to treatment resulting in socket contraction and subsequent frequent change of prosthesis and was presented finally with grade 2 of socket contraction requiring surgical intervention

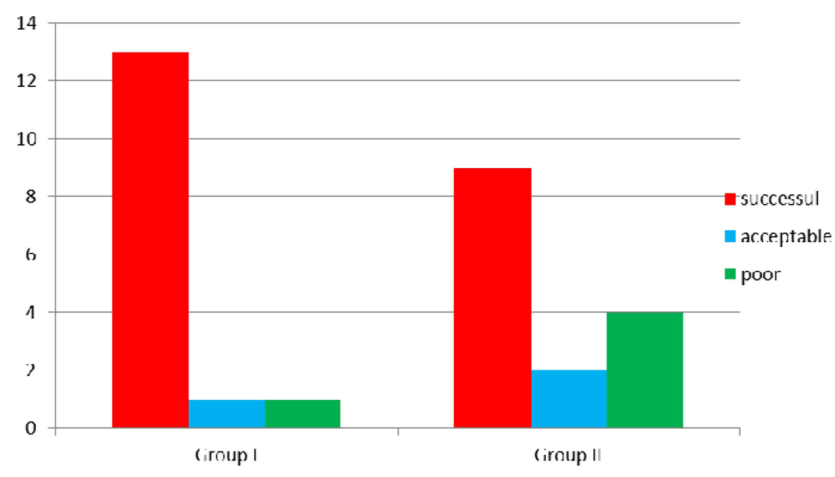

Figure 2 Column chart showing results of prosthesis fitting in both groups at the end of the sixth postoperative month.
(Figure 3A). Socket reconstruction with AMG was performed with adequate forniceal depth as seen in Figure $3 \mathrm{~B}$ and she received the conventional postoperative treatment in the form of antibiotic-steroid combination (Group I). Final prosthesis fitting was acceptable as shown in Figure 3C.

\section{Case 2:}

It was for a 44-year-old male patient, with history of evisceration due to traumatic endophthalmitis. He had received secondary ball implantation followed by prosthesis fitting. He dropped follow up then presented with contracted socket grade 2 seen in Figure 4A attributed to inappropriate wearing of the prosthesis as he gave history of frequent losing of the shell for prolonged periods and subsequent fitting with larger ones to compensate for the decreasing socket size. Socket reconstructive surgery with AMG was performed and he received the postoperative treatment with topical MMC in addition to the conventional medical treatment (Group II). Final prosthesis fitting was successful in Figure 4B and C.

\section{Discussion}

Contracted socket is caused by shrinkage of orbital tissues and leads to difficulty in prosthetic fitting with considerable functional and psychological morbidity. Socket contracture is manifested by foreshortening of the conjunctival fornices and/or loss of orbital SV. ${ }^{14}$

Adequate retention of the ocular prosthesis in the anophthalmic socket mainly requires a well-formed inferior fornix, which in turn needs sufficient conjunctival length and a deep recess. The treatment of a contracted socket is based on establishing adequate forniceal depth after removal of the cicatricial tissue and reconstruction with a graft. AMG is a well-established surgical technique for almost all degrees of contracted socket, with successful results. ${ }^{15,16}$

Even after careful planning and meticulous surgery, the repeated contraction of socket commonly occurs, causing 


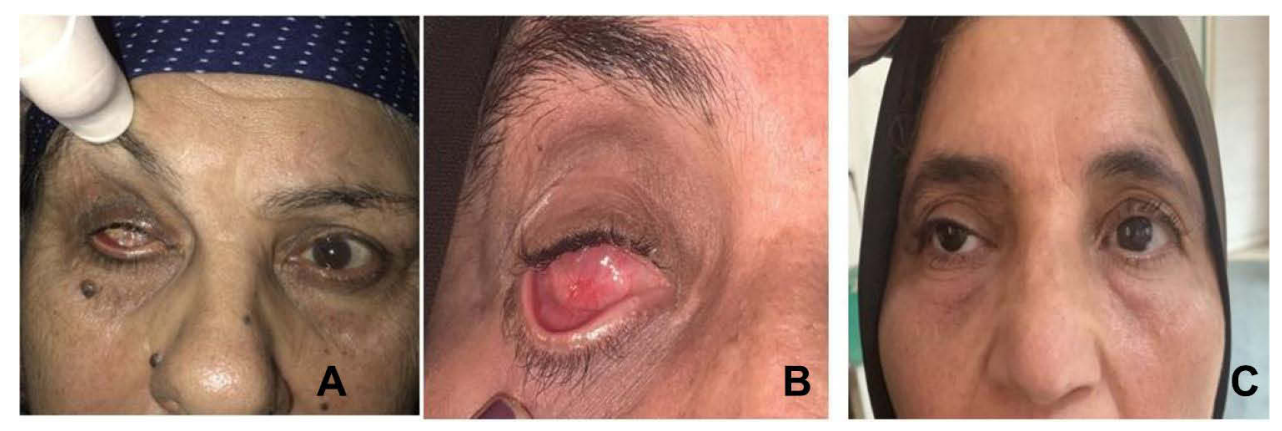

Figure 3 Case I. (A) Preoperative appearance with contracted socket grade 2. (B) Postoperative socket appearance with adequate fornix depth. (C) Postoperative acceptable prosthesis fitting.

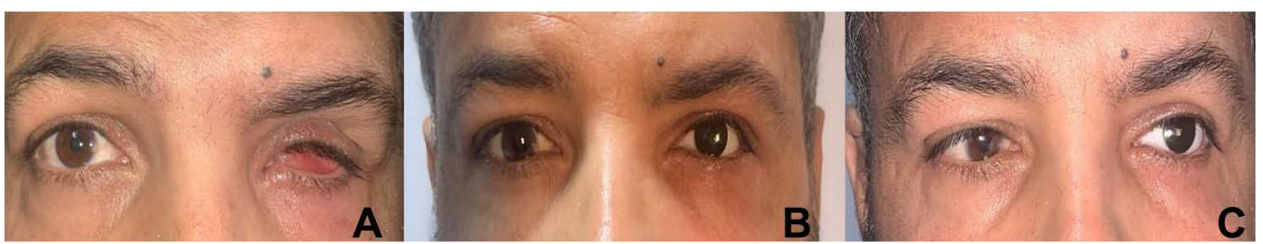

Figure 4 Case 2. (A) Preoperative appearance with contracted socket grade 2. (B) Postoperative successful prosthesis fitting. (C) Movement of the prosthesis with ocular movement without tilt.

shortening of the conjunctival fornices. Intraoperative use of antimetabolite agents (MMC and 5-FU) was studied in an attempt to prevent postoperative fibrosis by altering the biology of the wound healing with the ultimate goal of ocular prosthetic retention. ${ }^{17,18}$

Postoperative use of antimetabolites was also evaluated by other studies that focused on the injection of antimetabolites into the reconstructed conjunctival tissue, they are most useful when used in the early postoperative period, namely the first 4 postoperative weeks, when maximum healing and contraction occur. ${ }^{19-21}$ To the best of our knowledge, this is the first study that reports the results of postoperative use of topical antimetabolites (MMC eye drops) following socket reconstructive surgeries.

Priel et al $^{19}$ injected antimetabolites (5-FU $50 \mathrm{mg} / \mathrm{mL}$ or MMC C $0.4 \mathrm{mg} / \mathrm{mL}$ ) intra-operatively in the scarring area of contracted socket of five patients with additional postoperative injection in three of them. They found that the use of antimetabolites is effective in severe anophthalmic socket reconstruction with minimal side effects.

Kamal et $\mathrm{al}^{21}$ evaluated the efficacy and safety of repeated sub-conjunctival injections of 5-FU in the early postoperative period for recurrent contracted socket of 8 patients and they concluded that weekly injections of 5-FU are effective for stopping the progression of socket contraction following reconstructive surgery. It provides early rehabilitation and avoids repetitive surgeries.
In this study, topical MMC was used in 15 patients (group I) who underwent socket reconstructive surgery for 6 weeks, and the results were compared to those of another 15 patients (group II) who received the conventional postoperative antibiotic-steroid combination eye drops. Our results revealed that after maximum gain in all measured parameters at the first month following the procedure, patients in both groups showed gradual shrinkage and reduction in orbital volume and fornices depth, but this finding was more evident in group II, so that, at the final follow-up visit, there was a significant difference between the two groups in all measured parameters.

In the current study, we did not report any complications related to the usage of topical anti-metabolite therapy (such as allergic reaction, tissue necrosis or wound dehiscence) through the whole follow up period, which is comparable to the results of the studies conducted by Priel et al and Kamal et al. ${ }^{19,21}$

The main limitations of this study are its retrospective design, small sample size and relatively short follow-up period. Further prospective studies using larger samples would support our results.

In conclusion, postoperative use of topical MMC is associated with higher forniceal depth, greater SV when compared to the conventional postoperative treatment in socket reconstructive surgeries with AMG allowing the 
patients to have a cosmetically acceptable prosthesis with no reported complications associated with the procedure.

\section{Disclosure}

The authors report no conflicts of interest for this work.

\section{References}

1. Lee AC, Fedorovich I, Heinz GW, Kikkawa DO. Socket reconstruction with combined mucous membrane and hard palate mucosal grafts. Ophthalmic Surg Lasers. 2002;33:463-8.3. doi:10.3928/1542-887720021101-06

2. Kim CY, Woo YJ, Lee SY, Yoon JS. Postoperative outcomes of anophthalmic socket reconstruction using an autologous buccal mucosa graft. J Craniofacial Surg. 2014;25:1171-1174. doi:10.1097/ SCS.0000000000000807

3. Poonyathalang A, Preechawat P, Pomsathit J, Mahaisaviriya P. Reconstruction of Contracted Eye Socket with Amniotic Membrane Graft. Ophthal Plast Reconstr Surg. 2015;21:359-362. doi:10.1097/01. iop.0000179378.97762.c7

4. Slentz DH, Nelson CC. Novel Use of Cryopreserved Ultra-thick Human Amniotic Membrane for Management of Anophthalmic Socket Contracture. Ophthalmic Plast Reconstr Surg. 2019;35:193196. doi:10.1097/IOP.0000000000001264

5. Kumar S, Sugandhi P, Arora R, et al. Amniotic membrane transplantation versus mucous membrane grafting in anophthalmic contracted socket. Orbit. 2006;25:195-203. doi:10.1080/01676830600575527

6. AlHassan S, Galindo-Ferreiro A, Khandekar R, AlShaikh O, Schellini SA. Deepening fornix technique using central split-medium thickness skin graft to treat contracted anophthalmic sockets. J Craniofac Surg. 2018;29(6):1607-1611. doi:10.1097/SCS.0000000000004601

7. Van Der Meulen JC. Reconstruction of the socket. In: Van Der Meulen JC, Gruss JS, editors. Color Atlas and Text of Ocular Plastic Surgery. London, UK: Mosby-Wolfe,; 1996:275-297.

8. Demirci H, Elner SG, Elner VM. Rigid nylon foil-anchored polytetrafluoroetyhlene (Gore-Tex) sheet stenting for conjunctival fornix reconstruction. Ophthalmology. 2010;117:1736-1742. doi:10.1016/j. ophtha.2010.01.061

9. Palanca-Capistrano AM, Hall J, Cantor LB, et al. Long-term outcomes of intraoperative 5-fluorouracil versus intraoperative mitomycin $\mathrm{C}$ in primary trabeculectomy surgery. Ophthalmology. 2009;116:185-190. doi:10.1016/j.ophtha.2008.08.009
10. Camara JG, Bengzon AU, Henson RD. The safety and efficacy of mitomycin $\mathrm{C}$ in endonasal endoscopic laser-assisted dacryocystorhinostomy. Ophthal Plast Reconstr Surg. 2000;16:114-118. doi:10.1097/00002341-200003000-00005

11. Priel A, Oh S, Whipple KM, Korn BS, Kikkawa DO. Use of Antimetabolites in the Reconstruction of Severe Anophthalmic Socket Contraction. Ophthal Plast Reconstr Surg. 2012;28:409-412. doi:10.1097/IOP.0b013e3182627e86

12. Kamal S, Kumar S, Goel R, Bodh SA. Serial sub-conjunctival 5Fluorouracil for early recurrent anophthalmic contracted socket. Graefes Arch Clin Exp Ophthalmol. 2013;251(12):2797-2802. doi:10.1007/s00417-013-2478-1

13. Tawfik HA, Raslan AO, Talib N. Surgical management of acquired socket contracture. Curr Opin Ophthalmol. 2009;20:406-411. doi:10.1097/ICU.0b013e32832ed85b

14. Lee AC, Fedorovich I, Heinz GW, Kikkawa DO. Socket reconstruction with combined mucous membrane and hard palate mucosal grafts. Ophthalmic Surg Lasers. 2002;33:463.

15. Kim CY, Woo YJ, Lee SY, Yoon JS. Postoperative outcomes of anophthalmic socket reconstruction using an autologous buccal mucosa graft. J Craniofacial Surg. 2014;25:1171.

16. Bajaj MS, Pushker N, Singh KK, et al. Evaluation of amniotic membrane grafting in the reconstruction of contracted socket. Ophthalmic Plast Reconstr Surg. 2006;22:116-120. doi:10.1097/01. iop.0000200887.26015.d4

17. Lama PJ, Fechtner RD. Anti-fibrotics and wound healing in glaucoma surgery. Surv Ophthalmol. 2003;48:314-346. doi:10.1016/ S0039-6257(03)00038-9

18. Khaw PT, Sherwood MB, MacKay SL, et al. Five-minute treatments with fluorouracil, floxuridine, and mitomycin have long-term effects on human Tenon's capsule fibroblasts. Arch Ophthalmol. 1992;110:1150-1154. doi:10.1001/archopht.1992.01080200130040

19. Priel A, Oh S, Whipple KM, Korn BS, Kikkawa DO. Use of Antimetabolites in the Reconstruction of Severe Anophthalmic Socket Contraction. Ophthal Plast Reconstr Surg. 2012;28:409-412.

20. Tawfik HA, Abdulhafez MH, Fouad YA, Rashed HO, Osman WM Revisiting the role of the myofibroblast in socket surgery: an immunohistochemical study. Ophthalmic Plast Reconstr Surg. 2016;32 (4):292-295. doi:10.1097/IOP.0000000000000510

21. Kamal S, Kumar S, Goel R, Bodh SA. Serial sub-conjunctival 5Fluorouracil for early recurrent anophthalmic contracted socket. Graefes Arch Clin Exp Ophthalmol. 2013;251:2797-2802. doi:10.1007/s00417-013-2478-1
Clinical Ophthalmology

\section{Publish your work in this journal}

Clinical Ophthalmology is an international, peer-reviewed journal covering all subspecialties within ophthalmology. Key topics include: Optometry; Visual science; Pharmacology and drug therapy in eye diseases; Basic Sciences; Primary and Secondary eye care; Patient Safety and Quality of Care Improvements. This journal is indexed on PubMed
Central and CAS, and is the official journal of The Society of Clinical Ophthalmology (SCO). The manuscript management system is completely online and includes a very quick and fair peer-review system, which is all easy to use. Visit http://www.dovepress.com/ testimonials.php to read real quotes from published authors. 